\title{
Where Is Developmental Social Work as Social Work Practice Method in Tanzania? The Case of Dar es Salaam Region
}

\author{
William Manyama \\ Institute of Social Work, Tanzania \\ E-mail: williammanyama@yahoo.com
}

Received: June 5, 2018 Accepted: July 18, 2018 Published: July 20, 2018

doi:10.5296/ijsw.v5i2.13401ＵRL: http://doi.org/10.5296/ijsw.v5i2.13401

\begin{abstract}
There is a consensus that developmental social work method is increasingly gaining support as a panacea for social and economic problems facing the African continent. The main emphasis of the method is centered on pulling together community resources in addressing social and economic problems. The literature shows that the method is currently underutilized in Tanzania and the reasons propelling such a situation are not clear. This study has found that developmental social work is confronted with the following barriers in Tanzania: lack of resources, nature of social work training and curricula, organizational factors/nature of social service agencies activities, lack of innovation and absence of regulations/clear guidelines. The findings also suggest that in order to make full utilization of developmental social work, structural, institutional, professional and individual factors have to be addressed. The recommendations of this study are: developmental social work is very important so as to bring about social and economic development. The nature of economic and social problems facing vulnerable populations in Tanzania today requires a combination of different methods including that of developmental social work, if sustainable development has to be realized.
\end{abstract}

Keywords: Social work, Developmental social work, Social development, Social and economic development, Social work, Vulnerable population

\section{Introduction}

Developmental social work continues to gain considerable attention within the sphere of social work practice in Africa and Tanzania, in particular (see for example, Angion, 2003; Chitereka, 2009; Cox \& Pawar, 2005; Dei, 2002; Gray, Coates, \& Bird, 2005; Healy, 2008; Hochfeld, Kalinganire, \& Rutikanga, 2014; Ledwith, 2008; Lombard \& Wairire, 2010; Mabeyo, Ndung'u, \& Riedl, 2014; Midgley, 1995; Minkler, 2005; Ose-Hwedie \& Rankhopo, 
2008; Spitzer \& Twikirize, 2014; Selipsky, Mupedziswa, \& Chitereka, 2009; Viviene, 2009; Wairire, 2014). The method is synonymously used with social development approach. Scholars like Chitereka (2009), Green (2008) and Mupedziswa (2005) specifically noted that the problem with African social work is that it has over-utilized remedial/curative method in solving problems. This approach on its own, has proved failure in curbing problems of developmental nature i.e., poverty, unemployment, inadequate shelter, homelessness, illiteracy, disease and ignorance (Chitereka, 2009).

Developmental social work can be defined as a process of planned social change designed to promote the well-being of the population as a whole within the context of a dynamic multifaceted development process (Mingle, 2013). It aims to achieve social and economic justice through strengthening people and their communities' livelihood capabilities (Patel, 2005). Developmental social work was rooted in Africa (Midgley, 1995) and was widely applied to ameliorate social and economic problems facing Africa before the emergence of modern social welfare and social work practice (Mupedziswa, 2005; Mwansa, 2012). This developmental thinking and practice was implemented by the families, kinship and neighborhood to member groups through community participation and empowerment (Lombard \& Wairire, 2010).

In the western countries, it started with movements of community welfare center. The community welfare center movement began in the early $20^{\text {th }}$ century with the establishment of settlement houses and neighborhood centers in Europe and the United States (Taylor \& Roberts, 1985). The replacement of developmental social work with more social case work method in Africa is linked to the influence of colonialism and globalization (Spitzer \& Twikirize, 2014). This has created a vacuum in the provision of social welfare services because the services provided by social workers are not compatible with the developmental nature of the society, supported by relevant African cultures in specific contexts (Spitzer \& Twikirize, 2014). Jacobson (2001) argues that social work's emphasis on remedial solutions has become so dominant to the extent that many of the developmental activities such as: community organizing, social reforms and activism, advocacy, human capital development and community development programmes which have been long associated with social work profession are no longer called social work.

Other scholars such as Mupedziswa (2005) and Spitzer (2014) have further questioned on the relevance of social work relying on western based models in solving problems in the African continent and appeal to the region to see how developmental social work could/can contribute to solving social-economic problems facing the continent. Although not explicitly stated in the literature, available evidence shows that developmental social work thinking was very instrumental towards achieving African social and economic development after attaining independence i.e., ujamaa and self-reliance was applied in Tanzania, harambee in Kenya and ubuntu in south Africa, to mention a few, were focusing on helping the vast majority of the vulnerable population using community resources (Spitzer, 2014).

The need for restoring developmental social work (social development approach) in African countries was reiterated during the Copenhagen meeting in 1995, where there was a declaration on placing people at the center of development/treating people as subjects of development and not objects of development. It was also expected that this approach would 
facilitate the attainment of the eight Millennium Development Goals in 2001 (United Nations [UN], 2005).

As already pointed out by Spitzer (2014), in Tanzania, developmental social work method was unconsciously employed when Tanzania decided to adopt socialism and self-reliance, as a governing political ideology. The primary intention of this method was to pool together the community efforts and resources and facilitate the provision of social welfare services (Ibhawoh \& Dibua, 2003). This enabled the community to access a wide-range of free basic education and health service to all people (Nyerere, 1977). One can correctly argue that developmental social work method under Mwalimu Nyerere was meant to enhance the spirit of togetherness, trying to up-hold the African ways of helping each other in their communities and that the state will provide support when people are in groups.

To put this ideology into practice, villagization campaign was employed, where many social service workers were engaged in assisting the communities to identify their resources, work and develop together for their betterment (Nyerere, 1977; Okoko \& Kimse, 1987). One can correctly postulate that in Tanzania, elements of developmental social work method preceded the formal social work training which was started during the 1970s. The unintended consequence of formal social work education which was/is western oriented was that most of the social work practitioners became engulfed with case work approach. Spitzer (2014) argues that the conditions which gave rise to the development of social work in Europe were quite different from those of the African context and hence developmental social work would be so appropriate to tackle the African problems. Thus, the escalating degree of social problems, with multifaceted shapes in Tanzania, compels the East African countries to turn to developmental social work (Spitzer, 2014).

However, despite the relevance of developmental social work method, the little evidence available shows that developmental social work method is under-utilized, without stating why. The only seminal work of Mabeyo et al., (2014) ranked developmental social work method at the bottom of social work practice in Tanzania. Mabeyo's et al., (2014) research in Tanzania depicted that most of social workers $(70 \%)$ were predominantly using case work method and entrenched with counseling while $18 \%$ were dealing with developmental social work method. However, this piece of literature did not state why developmental social work method was/is not properly utilized in Tanzania and alternatives that can make it work better. This study would like to fill this gap by examining the barriers to the application of developmental social work method in Tanzania and the way to make it more applicable. The main objective of this study was to be realized by: examining social workers knowledge and perceptions towards developmental social work, identifying challenges faced by social workers on the utilization of developmental social work and exploring social workers' suggestions on improving the utilization of developmental social work.

\section{Literature Review}

Lombard and Wairire (2010) conducted a study to explore the extent to which developmental social work method was utilized in South Africa and Kenya. The Lombard's and Wairire's (2010) study found that there was variation in terms of utilization of developmental social work between South Africa and Kenya. In South Africa, it was found that developmental social work method to social welfare had recorded great progress because of efforts done by 
social workers in the country, in collaboration with NGOs. The process started with a submission to the Truth and Reconciliation Commission in 1998 on the social welfare sector's contribution to the abuse of human rights during apartheid (Patel, 2005; Lombard, 2000 cited in Lombard \& Wairire, 2010).

On the level of implementation, specific policies have been developed to put into practice the White Paper for Social Welfare, including, inter-alia, the Financial Policy for Developmental Social Services (1999) and the Integrated Service Delivery Model (2006). Current legislation pertaining to children, senior citizens, social assistance and domestic violence was amended or new legislation developed. However, despite the progress made in providing policy and a legislative framework, there are still many challenges ahead in shaping and institutionalizing policies for the effective implementation of developmental social work method. For example, the revision of financing policies to support developmental welfare strategies is a burning issue, as these are currently not adequately funded (Patel \& Hochfeld, 2008 cited in Lombard \& Wairire, 2010) in the absence of national norms and standards for service delivery. The funding challenge directly relates to the partnership embedded in developmental social work (Lombard \& Wairire, 2010).

The same study by Lombard and Wairire (2010), found out that developmental social work method was very lowly employed in Kenya because there was no single comprehensive legislative act or policy that directly and specifically confines itself to developmental social work method in Kenya. Social work in Kenya is still a growing profession; social work training institutions are limited in number and are unable to meet the country's demand for social work professionals. The upshot of the limited numbers of social workers in the country is that they have not been able to lobby strongly for a legislative Act of parliament that could give developmental social work in Kenya a new face and public recognition. Worse still, due to the limited numbers of social work professionals, many social work tasks and roles end up in the hands of non-social work personnel. The most notable framework for developmental social work in Kenya is the Economic Recovery Strategy for Wealth and Employment Creation (ERS), which played a major role in the recovery (albeit slow) and growth of Kenya's economy. The growth was not only positive for education, health, gender and the environment but also provided more resources for meeting the Millennium Development Goals across the economy (GoK, 2008).

Another study was conducted by Mabeyo, Ndung'u and Riedl (2014) in Tanzania. The study confirms over reliance of case work method in social work practice (70\%) while developmental social work method is applied at $18 \%$ only. As such, interventions do not end in creating long term solutions and generally improving clients' socio-economic conditions.

Summarizing the research gap, it would be sensible to say that the relevance of Lombard's and Wairire's (2010) work is that it clearly indicates the conditions for the realization of developmental social work, citing South Africa and Kenya as case studies. Since the setting of Lombard's and Wairire's work is South Africa and Kenya, it would also be interesting to find out the barriers to the utilization of developmental social work method in Tanzania. Further, the study by Mabeyo et al., (2014) did not clearly explain why and how developmental social work method is lowly applied in Tanzania. This limitation further underlines the importance of conducting a study examining the status and barriers to the 
utilization of developmental social work method in Tanzania, which will bring to the surface social workers' concerns that affect their interventions and the way to address them.

\section{Methods}

This article adopted a descriptive qualitative research design to get detailed information on social workers' perceptions, views and experiences on utilizing developmental social work method in Tanzania. The population of this study involved social workers employed by both Government and NGOs. Non-probability sampling procedure and purposive sampling techniques were employed in this study. In this study, 16 participants were involved in semi-structured interviews. Further, thematic data analysis was adopted as a strategy for analyzing data. Three researchers were engaged in data collection and two were involved in coding the data. Semi-structured interview sessions took between 30 minutes and one hour. The information gathered from the interviews were recorded and some written in note books. The interview sessions were conducted in Swahili language and were conducted at the participants' premises. Participants were social workers employed by the government and NGOs. Whereby nine (9) participants were government employees and seven (7) participants were drawn from NGOs. The participants had vast experiences in social work practice.

Research clearance/permit was sought from the Institute of Social Work. While undertaking this study, the following ethical principles were observed: informants' right to informed consent, avoiding psychological torture and to clearly inform the participants that the information required was for generation of knowledge which can contribute to bettering social work professions role in the country.

\section{The Findings}

This section presents and discusses the findings of the study. The findings presented here reflect the three specific objectives namely: social workers' knowledge and perceptions towards developmental social work method, barriers to the utilization of developmental social work method and social workers suggestions so as to smoothly integrate developmental social work method in social work interventions.

\subsection{Social Workers Knowledge and Perceptions Towards Developmental Social Work Method}

According to the findings, the term developmental social work method, sounded familiar to the informants, notwithstanding that they interpreted the development social work concept in different ways. 10 out of 16 informants were of the opinion that developmental social work method is the same as community development in many aspects; it is people centered approach aimed at bringing about social change. However, differences emerged when the informants talked on how developmental social work method is applied. This is illustrated in the following quotes:

I can say that developmental social work method is almost the same as community development. Activities related to developmental social work are like poverty alleviation projects i.e., formation and supervision of income generation groups.... (Male social worker, 39 years, Government employee)

Developmental social work looks similar in many ways to community development. The only difference is that community development is more of campaign while developmental social work is more of doing things together with the community for change (Male social worker, 37 
years, NGO employee)

Other informants mentioned the activities related to developmental social work method. They had the following to say:

Developmental social work is related to things like provision of HIV/AIDs education to groups of people, group counseling services etc. (Male social worker, 39 years, Government employee)

.....are those actions aimed at assisting individuals to enhance their well-being i.e., assisting people to get food and other basic needs (Female social worker, 31 years, Government employee)

To be honest, I am applying very little knowledge of development social work...this is applicable to those social workers who deal with rehabilitation and probation services....(Male social worker, 41 years, Government employee)

The analysis shows that the participants were knowledgeable about developmental social work method as they were able to cite or give relevant examples on how developmental social work method works. With regard to social workers' perceptions towards developmental social work method, the informants differed in terms of how they viewed it. Five (5) out of 16 informants viewed it as a relevant method that helps to realize sustainable social and economic changes as shown in the following quote:

I view developmental social work method positively. This is because it is responsive to many problems currently facing our clients because of capacity building programmes. With capacity building, communities, families and individuals are empowered to fight against poverty, HIV/AIDS, diseases, unemployment, poor housing within their local environment by being supported with either resources or trainings (Female social worker, 46 years, Government employee)

However, six (6) out of 16 informants had a view that developmental social work method is more applicable in community development settings as depicted in the following quote:

As a social worker, I do not use much this method as most of my activities are related to individuals' problems like matrimonial conflicts while community development concerns community development officers (Male social worker, 32 years, Government employee)

Developmental social work method is relevant but given the nature of our everyday activities, I view it as a responsibility of community development officers (Government employee, 36 years)

Other informants pointed out that capacity building progarmmes should be carried out in order to make social workers utilize developmental social work method. The following informant shared that sentiment

I think we need to have refresher courses so as to clear doubts surrounding developmental social work method (Government employee, 39 years)

The findings show that social workers view developmental social work method differently and this has implication on the social welfare service provision. For example, viewing developmental social work as the role of community development officers, it implies that the vulnerable segment population is not assisted to employ collective action/strategies in order 
to develop themselves socially and economically. The findings of the present study confirm the findings of the previous studies by Gray (2006), Lombard (2007) and Patel (2005). Looking at those who thought that developmental social work is more applicable in community development settings, Gray (2006) and Lombard (2007) contend that social workers should not only focus on individuals when providing service but rather they should play a stimulating role to the community to become aware of the problems facing them and eventually take actions. Further, Patel (2005) has also identified the gaps between social work interventions and community participation. Patel asserts that one of the key weaknesses of the interventions traditionally favored by case work method is its inability to challenge the wider structures of marginalization and impoverishment.

\subsection{Challenges Faced by social Workers on the Utilization of Developmental Social Work} Method

Despite the fact that the participants held positive views and approved the use of the developmental social work method, they realized that their aspiration to implement it encountered many challenges, including the following: high caseloads, lack of resources both human and financial resources, absence of legislative act, clients mentality, lack of innovation and nature of social work training and curricula.

\subsubsection{Overburden With High Caseloads}

According to the findings, social workers are working in a very challenging and frustrating environment and yet there is no special attention and reasonable degree of seriousness shown by the government. The participants firmly emphasized that the professional working conditions tend to hinder the implementation of developmental approach to social work. The informants had the following sentiments:

...we are overwhelmed with cases i.e., matrimonial and maintenance cases from morning to evening... and sometimes we work beyond the normal working hours. Honestly, there is too much to do such that we cannot think of applying developmental social work! (Female social worker, 37 years, Government employee)

Working as a social worker is like a church business...no time to rest and yet there are people who complain that our contribution is not known... and because of this some of social workers are looking for green pastures... with the high caseload one has, there is no way I can think of doing activities related to developmental social work method. Much of what we are doing is matrimonial, maintenance, foster care and adoption issues etc... (Male social worker, 42 years, Government employee)

Cases concerning child welfare are very sensitive and time consuming...suppose you have three cases, you cannot think of developmental social work method which is much more concerned with economic development (Female social worker, 38 years, Government employee)

Other social workers voiced their concern that they were few in number and yet there was too much expected from them:

I know how developmental social work is applied but the problem is that the number of social workers does not suffice the needs. So, it is difficult to do each and everything (Male social worker, 34 years, Government employee) 
Apart from that, some of the participants voiced their frustration of the fact that they need to constantly fill in statistics forms with the total numbers of clients they had served. The informants reported that these kinds of tasks left no room for developmental social work method.

In our organization, employee performance is determined by the number of cases he or she had administered. So, you will find yourself coming to the office everyday with the same tasks. By doing so, activities related to developmental social work are rarely carried out (Female social worker, 32 years, NGO employee)

As the last quote indicates, gauging ones commitment in solving problems basing on the number of cases he or she has attended is a big challenge towards realizing developmental social work method among the social workers. Overburden with high caseloads is equally another barrier to implement developmental social work method. A similar observation has been made by Kang'ethe (2014) who pointed out that social work in Africa is constrained with high case load while their workforce is small. As such, most of them end up being frustrated by their tight schedules, which in turn compels them to stay in their offices, solving the clients' problems as their daily routine. Kang'ethe concludes by holding that beyond application of developmental social work method, social workers are overburdened with clients' cases, some of them get stressed, face burnout and treat their clients unethically, not friendly and thus affecting their services.

\subsubsection{Nature of Social Work Training/Curricula}

Discussions with the informants also showed that developmental social work method is lowly utilized in their interventions due to the nature of social work training and education. The informants had the views that although they had been taught many methods of social work i.e., social administration, case work, group work and community work, great emphasis was mainly placed in casework method. The informants had the following sentiments:

I would like to tell you that most of the social workers are engaged in direct practice social work which utilizes case work method because much of what is taught is touching that method. Other methods like social administration, community work etc. are mere single modules (Female social worker, 39 years, Government employee)

We are more inclined to casework method because most of the teaching is on social case work. Other methods like community work/developmental social work do not receive due attention (Male social workers, 36 years, Government employee)

Other informants added that:

Case work is highly emphasized, look at the fieldwork reports. Most students are told to write at least two or three cases. So, students go to the field with a mindset of either meeting matrimonial or affiliation cases. What do you expect after completing their fieldwork? (Female social worker, 33 years, NGOs employee)

Other informants highlighted on missing specialized trainings on postgraduate courses that directly deal with developmental social work. This is evident in the following sentiments:

I think, we are missing a link of further studies on developmental social work. It is mostly taught in undergraduate studies. We need it at postgraduate level as well, so that to produce the expected outcomes (Male social worker, 33 years, NGOs employee) 
Developmental social work is taught at undergraduate levels only. There has to be a connection with postgraduate studies as well for equipping students with more specialized skills (Male social worker, 37 years, Government employee)

The relegation of developmental social work method has also been discussed by numerous scholars. Tan (2009) argued that developmental social work method has received very little attention in most of the social work curricula in terms of instructions, policy and practical environment. As such, social work instructors in many social work programmes are biased towards micro practice. Du Preez (2007) further points out that paradigms shift by all social workers are needed. She emphasized that in order to implement the new paradigm; there should be appropriate training and education for social workers and re-orienting in service social workers to developmental social work. Semali and Stambach (1997) argue that in many developing countries, social work education continues to be dominated with western-based models which have raised concerns on their suitability, especially in making social work training more learner-centered.

Indeed, as emphasized by Rankopo and Osei-Hwedie (2011), relevant social work education must strive towards embracing multiple perspectives and cultural explanations of social reality and this can best be addressed by utilizing more developmental social work. Abah, Mashebe, and Denuga (2015) offer a solution on how to take on board developmental social work. They argue that African indigenous knowledge systems are very relevant on promoting social and economic sustainability. Therefore, social work educators and students as curriculum implementers need to conduct research and take into consideration on what developmental issues have been prioritized in the local communities, if social and economic sustainability has to be attained. There is general agreement that in Africa, indigenization has much to do with adopting a developmental approach to social work as well as generation and respect for indigenous helping processes through culturally relevant practice (Twikirize et al., 2014).

\subsubsection{Absence of Legislative Act/Guideline}

The informants shared that there was no any legislative act/guideline/policy that give them a mandate to use developmental social work method in Tanzania. The informants' answers were drawn from the current statutory duties that most social workers have. The foregoing is depicted in the following quotes:

It is really a challenge, we are not obliged by any policy to use developmental social work method...it becomes easier to deal with issues like child protection because there is an act and a policy that specifically direct us what to do (Female social worker, 36 years, Government employee)

It is difficult to use something which is not supported by any act... (Male social worker, 45 years, Government employee)

However, social workers employed by the NGOs were not very much concerned with legislations. Their primary objective was to find a way to assist individuals, families and communities in order to improve their lives.

.....well, issues of legislation matters but our main thrust is to assist the entire community by working together with them. We are not solely responsible to provide people with things like 
money or consumer goods but rather to empower people through capacity building programmes and putting pressure on the government to implement their promises (Male social worker, 39 years, NGO employee).

What can be established from the above quotes is that developmental social work method can best be implemented through guidelines/policies/acts that promote human capital development, encourage the social inclusion of people in the development process through skills training and education, and invest in building the capacities of poor people to participate productively in the economy through human capital development (See also, Sewpaul, \& Rollins, 1999; Midgley \& Tang, 2001; Lombard, 2003; Patel, 2005).

\subsubsection{Lack of Innovation}

The findings also showed that one of the barriers to developmental social work method is lack of creativity among the social workers. The informants had the following explanations with regard to this point:

We have to be honest, reluctance is one of the factors for low utilization of developmental social work method .... when people are employed they simply copy what others are doing. It is business as usual! This would have not been a big problem if people are thinking and acting (Female social worker, 39 years, Government employee)

Lack of creativity makes us do the same things every day (Male social worker, 37 years, Government employee)

Other informants pointed fingers to the Department of Social Welfare as illustrated in the following quotes:

...lack of innovation in this profession starts with the governance of social welfare system itself...from the top people do not see any potential changes. Things are getting worse as days go by. They say changes starts from below but I am saying changes should start from above (Male informant, 46 years, Government employee)

We have to blame ourselves; I do not think if we remember our vision and mission. Perhaps we need refresher courses so that we improve the lives of the people through developmental social work (Female social worker, 35 years, Government employee)

Leterrier (2000) cited in Chitereka (2009) argues that social work is not important if there is no development. If social work profession really wants to solve the problems of people, it has to work for people's economic development, under the facilitation and assistance of social workers. In order to ensure effectiveness and sustainability in social and economic development, social workers have to collectively work with the local communities to solve problems of common concern, using the resources available, and that is meaningful development Leterrier (2000) cited in Chitereka (2009).

\subsubsection{Clients' Mentality}

The findings depicted that client mentality was considered as a stumbling block to social workers. Social workers pointed out that they try their level best to educate their clients on developmental social work issues in solving problems, but some of their clients do not show commitment to that method. They are waiting for services which are provided free of charge i.e., money and food. The following quotes testify that: 
There are many problems on the side of our clients. I would like to accentuate this point that most of them like to get goods and services for free! Some of them are extremely lazy; they do not do anything to meet their everyday needs and worse still they are the ones who complain that life is difficult! There are men who are considered as bread winners in their families but still need support from the social welfare office despite the training they had been given (Female social worker, 37 years, NGO employee).

Another informant remarked:

My perspective is very clear that these people have capability of changing their lives. I have a couple of examples to show that if these people work hard, they can overcome the phenomenon of poverty. We have found other people forming self help schemes and revolving the money or contributing the money in turns among themselves. This has been like a tradition now. For example, a group known as Amani Youth Group started earlier to save their money through participating in masonry and carpentry with weekly contributions per member from 4 to 6 thousands Tshs depending on their weekly income. This is very wonderful. The number of people participating in the scheme is currently 10 to 12 (Male social worker, 48 years, NGO employee).

This implies that some of the social workers are determined to help the people and have many good things to offer if they are given corporation from their clients.

\subsubsection{Resources Constraints}

This is considered to be the major problem facing social workers in Tanzania. Social workers have many areas to intervene that involve financial, material and man power support but they find themselves having less than what is required. One of the informants had the following to tell:

I would like to tell you that one of the problems is inadequate funding to run the developmental social work projects. We tried to initiate some but we failed.... The budget allocated for social welfare department is very little. The little resources available are used to assist individuals i.e., older people, youth who come to the office. We as social workers, we do not get any gain out of this work, rather than being frustrated, we call it a mission! (Social worker, 46 years, Government employee)

Developmental social work requires some money as most of the activities are run on outreach basis....we are not paid even money for transport! How will I manage to do that? The problem is that the government is yet to recognize the value of this profession. I am telling you, people are frustrated and are searching for other jobs; some are going to the NGOs (Female social worker, 34 years, Government employee)

The participants were also frustrated with the fact that they are expected to be innovative and come up with new programmes but when they finally do that they are told that there is no funding to implement such developmental programmes; these factors discouraged the social workers' morale, as one of the participants said:

We sometimes try to be innovative and think outside the box by designing new social development projects. However, instead of supporting us, they tell us that there is no funding. The problem is that they are not recognizing our role! (Female social worker, 42 years, Government employee) 
Another problem related to financial position concern social workers employed by the NGOs. The informants pointed out that they depend on the support from international partners which makes their future operation or sustainability questionable. Their budget relies to a large extent on donor contributions by implications. This results in inefficiency of the NGOs when the donor funds are delayed or not available.

Quite often, we have failed to complete some of the social development projects!. And yet most of our clients still claim that we have money.... (Social worker, 47 years, NGO employee)

The findings clearly show that there is unreliable financial base impact on social workers interventions. Moreover, this also implies also that social workers have little resource mobilization skills and do not consider the fund that is locally available to support their activities instead they are totally relying on donors funding. Using the experiences of South African social workers, Lombard and Wairire (2010) assert that launching campaigns and protests in collaboration with NGOs were some of the strategies used by social workers to make their voices heard to the authority. This brought a significant impact for developmental social work as the government acknowledged, increased the budget and declared social work as an important profession.

\section{Conclusion}

This article focused on the three specific objectives namely: social workers' knowledge and perceptions towards developmental social work method, barriers to the utilization of developmental social work method and social workers suggestions so as to smoothly integrate developmental social work method in social work interventions. According to the findings, social workers are knowledgeable on developmental social work method and view the method positively. However, despite such knowledge and perception developmental social work is lowly applied in Tanzania. This is due to the fact that social workers are involved in social cases and lesser in economic aspects that require the attention of developmental social work, influence of social work training and education, reasons related to individual's spirit of creativity, organizational/institutional/agency interest, resources and high caseloads. The last specific objective is embodied in the recommendation section of this article.

\section{Recommendation}

According to the findings, social workers are required to make a paradigm shift towards a developmental social work method and that the paradigm shift requires change of social workers mindset (See also Rankin, 1997; Forward, 2003). However, for this to be successful there has to be improvement in social work curricula/training. Second, refresher courses/capacity building programmes should be implemented so as to provide social workers with crucially important skills on developmental social work, in order to stimulate such a paradigm shift. Third, there has to be a conducive legislative environment that permits uptake of developmental social work practices. Fourth, social workers need to have specialized trainings on developmental social work at postgraduate levels. Fifth, the Department of Social Welfare has to establish mechanisms that will make the integration of developmental social work in social workers' daily activities easier. 


\section{Acknowledgement}

I would like to extend my sincere appreciations to the Management of the Institute of Social Work for providing me with research permit which facilitated access to both Government and NGOs offices during the data collection exercise.

\section{References}

Abah, J., Mashebe, P., \& Denuga, D. D. (2015). Prospect of Integrating African Indigenous Knowledge Systems into the Teaching of Sciences in Africa: American Journal of Educational Research, 3(6), 668-673.

Angioni, G. (2003). Indigenous knowledge: Subordination and localism. In G. Sanga, \& G. Ortalli (Eds.), Nature, Knowledge: Ethno science, cognition, and utility (pp. 287-296). New York: Oxford.

Boesen, J., Madsen, B.. \& Moody, T. (1977). Ujamaa: sociolism from above. Uppsala: Scandnavian Institute of African studies.

Bracht, N. F. (1999). Health promotion at the community level: new advances. Thousand Oaks, California, Sage Publications.

Chitereka, C. (2009). Social work practice in a developing continent: The case of Africa. Advances in Social Work, 10(2), 144-156.

Cox, D., \& Pawar, M. (2005). International Social Work: Issues, Strategies and Programs. California: Sage Publications.

Conradie, I. (2008). Agency and capabilities. Cape town: University of the Western Cape.

Dei, S. G. J. (2002). African development: The relevance and implications of indigenousness. In G. J. S. Dei, B. L. Hall, \& D. G. Rosenberg (Eds.), Indigenous knowledge in global contexts: Multiple readings of our world (pp. vii-x). Toronto: University of Toronto Press.

Dominelli, L. (2002). Anti-oppressive social work theory and practice. New York: Palgrave Macmillan. https://doi.org/10.1007/978-1-4039-1400-2

Dominelli, L. (2009). Repositioning social work. In R. Adams, L. Dominelli, \& M. Payne (Eds.). Social work: Themes, issues and critical debates. (3rd ed.) New York, Palgrave Macmillan. https://doi.org/10.1007/978-1-137-08215-2_5

Government of the Republic of Kenya [GoK]. (2008). Millennium Development Goals; Status Report for Kenya-2007. Retrieved from http://www.ke.undp.org/content/kenya/en/home/post-2015/mdgoverview.html

Gsanger, H. et al. (1992). Beyond traditional solidarity. Self-help and social security in rural Pakistan. Berlin, Germany Development Institute.

Gray, M., Coates, J., \& Bird, M. Y. (Eds.). (2005). Indigenous social work around the world. Cornwall: Ashgate.

Green, S. (2008). Perspectives of some non-governmental organizations on progress towards developmental social welfare and social work. The Social Work Practitioner-Researcher, 20(2), 174-191.

Healy, L. N. (2008). International social work: Professional action in an interdependent world. New York: Oxford University Press. https://doi.org/10.1177/0020872808095247 
Hochfeld, T., Selipsky, L., Mupedziswa, R., \& Chitereka, C. (2009). Developmental Social Work Education in Southern and East Africa. Johannesburg, Center for Social DevelopmentUniversity of Johannesburg.

Ibhawoh, B., \& Dibua, J. (2003). Deconstructing Ujamaa: The legacy of Julius Nyerere in the quest for social and economic development in Africa. African Journal of Political Science, $6(1), 59-83$.

Ife, J., \& Tesoriero, F. (2006). Community development: community-based alternatives in an age of globalisation. Frenchs Forest: Pearson Education Australia.

Kang'ethe, S. M. (2014). Exploring Social Work Gaps in Africa with Examples from South Africa and Botswana: $J$ Soc Sci, 41(3), 423-431. https://doi.org/10.1080/09718923.2014.11893377

Ledwith, M. (2005). Community development: A critical approach. Bristol: Policy Press.

Mabeyo, Z. M., Ndung'u, E. M., \& Riedl, S. (2014). The role of social work in poverty reduction and the realization of millennium development goals in Tanzania. Kampala: Fountain publishers.

Midgley, J. (1995). Social development: The development perspective in social welfare. London: Sage Publications.

Midgley, J. (2010). The theory and practice of developmental social work. In J. Midgley, \& A. Conley (Eds). Social Work and Social Development (pp. 3-28). Theories and Skills for Developmental Social Work: Oxford University Press. https://doi.org/10.1093/acprof:oso/9780199732326.003.0001

Minkler, M. (2005). Community organizing and community building for health. Piscataway: Rutgers University Press.

Nyerere, J. (1977). The Arusha declaration ten years after. Dar es salaam: The Govt. Printer. Okoko, K. A. B. (1987). Socialism and self-reliance in Tanzania. London and New York: KPI Limited.

Osei-Hwedie, K., \& Rankopo, M. (2008). Developing culturally relevant social work education in Africa: The Case of Botswana. In M. Gray, J. Coates, \& M. Y. Bird (Eds.), Indigenous social work around the world (pp. 203-219). Cornwall: Ashgate.

Rankopo, M. J., \& Osei-Hwedie, K. (2011). Globalization and culturally relevant social work: An African perspective on indigenization. International Social Work, 54(1). https://doi.org/10.1177/0020872810372367

Spitzer, H., \& Twikirize, J. M. (2014). A vision for social work in east Africa. In H. Spitzer, J. M. Twikirize, \& G. G. Wairire (Eds.). Professional social work in east Africa (pp. 232-244). Kampala, Fountain publishers.

Tan, A. (2009). Community development theory and practice: bridging the divide between 'micro' and 'macro' levels of social work. Presented at: NACSW Convention 2009 October, 2009 Indianapolis, IN.

Viviene, E. C. (2009). The changing nature of social work. In R. Adams, L. Dominelli, \& M. 


\section{Macrothink}

International Journal of Social Work

ISSN $2332-7278$ 2018, Vol. 5, No. 2

Payne (Eds). Social work: Themes, issues and critical debates. (3rd ed., pp. 26-33). New York, Palgrave Macmillan.

Wairire, G. G. (2014). The state of social work education and practice in Kenya. In S. Twikirize \& Wairire (Eds.) Professional social work in east Africa: Towards social development, poverty reduction and gender equality (pp. 93-107). Kampala, Fountain Publishers.

Kalinganire, C., \& Rutikanga, C. (2014). Social development as the privileged model for social work practice in post-genocide Rwanda. In Spitzer, Twikirize, \& Wairire (Eds.) Professional social work in east Africa: Towards social development, poverty reduction and gender equality (pp. 232-244). Kampala, Fountain publishers.

United Nations [UN]. (2005). The Social Summit: Ten Years Later. Department of economic and social affairs, New York, United Nations. Retrieved from http://www.un.org/esa/socdev/publications/SocialSummit-10YearsLater.pdf

United Nations Development Programme [UNDP]. (2016). Tanzania Human Development Report: Economic Transformation for Human Development. Dar es Salaam: Economic and Social Research $\quad$ Foundation. Retrieved from http://hdr.undp.org/sites/default/files/thdr2014-main.pdf

\section{Copyright Disclaimer}

Copyright reserved by the author(s).

This article is an open-access article distributed under the terms and conditions of the Creative Commons Attribution license (http://creativecommons.org/licenses/by/3.0/). 